\title{
Retrogression and re-ageing of 7075 aluminium alloy: microstructural characterization
}

\author{
F. Viana ${ }^{\mathrm{a}, *}$, A.M.P. Pinto ${ }^{\mathrm{b}}$, H.M.C. Santos ${ }^{\mathrm{a}}$, A.B. Lopes ${ }^{\mathrm{c}}$ \\ ${ }^{a}$ GMM/IMAT, Dep. Eng. Metalúrgica, Fac. Engenharia da U.P., Rua dos Bragas, 4099, Porto Codex, Portugal \\ ${ }^{\mathrm{b}}$ Dep. Eng. Mecânica, Escola de Engenharia da U. Minho, 4800, Guimaraès, Portugal \\ ${ }^{\mathrm{c}}$ Dep. Eng Cerâmica e do Vidro da U. Aveiro, 3800 Aveiro, Portugal
}

\begin{abstract}
Industrial Summary: The 7075 aluminium alloy presents a low stress corrosion cracking strength when aged to achieve maximum mechanical strength, T6 temper; high stress corrosion cracking strength is attained with overageing, T7 temper; but with loss of mechanical strength. Retrogression and re-ageing treatments improves the stress corrosion behaviour of the alloy whilst maintaining the mechanical resistance of the $\mathrm{T} 6$ temper. The microstructures produced by the retrogression and re-ageing treatments were characterized in this study by transmission electron microscopy, electron diffraction and differential scanning calorimetry. The precipitation is extremely fine and distributed homogeneously inside the grains, being slightly denser and more stable than that resulting from the T6 temper; whilst the grain boundary precipitation is quite different from that resulting from T6 treatment, the particles being coarser, and much closer to the precipitation resulting from $\mathrm{T} 7$ temper. The retrogression temperature is the main property controlling factor; a higher retrogression temperature, increasing the dissolution degree, promotes the formation of more stable precipitates on re-ageing. (C) 1999 Elsevier Science S.A. All rights reserved.
\end{abstract}

Keywords: 7075 aluminium alloy; Heat treating; Retrogression; Re-ageing; Microstructures

\section{Introduction}

The study of the influence of the retrogression and reageing heat treatments (RRA) on the mechanical properties and microstructure of 7075 alloy has been reported in previous papers [1,2]; these references show that RRA are capable of producing a material with mechanical and stress corrosion strengths higher than those presented by the T6 temper; this remaining true even for a lower range of retrogression temperatures (from 160 to $220^{\circ} \mathrm{C}$ ) than that recommended in the literature $\left(220-280^{\circ} \mathrm{C}\right)$.

RRA consist of applying to the alloy in the T6 temper a double stage thermal cycle: the first stage (retrogression) runs at higher temperature and is followed by a stage similar to that used to obtain the T6 temper (re-ageing). The duration of the first higher temperature stage is the necessary for the maximum solution of the T6 precipitates to occur; a minimum mechanical strength is being associated with this temper. During the second lower temperature stage (the re-

*Corresponding author: Tel.: +351-2-2041784; fax: +351-2-2041792 E-mail address: fviana@fe.up.pt (F. Viana) ageing treatment) the solute re-precipitates and the mechanical strength increases again [3,4].

The high mechanical strength developed by the alloy in the T6 temper is associated with a high density metastable precipitation, distributed homogeneously in the aluminium matrix; whilst a lower density of thicker precipitates, more stable in nature, is the microstructure responsible for the inferior strength of the overaged $\mathrm{T} 7$ temper.

Whilst maintaining the T6 temper microstructure inside the grains, RRA treatments promote coarsening of grain boundary precipitation; this microstructure becomes similar to that of the T7 temper; the overall microstructure being more stable in nature than that for the T6 temper.

The high density of fine precipitates is responsible for the high mechanical strength achieved with these treatments.

The stress corrosion resistance of the alloy is generally thought to be controlled by the microstructure near to grain boundaries (the size and spacing of precipitates, free precipitation zones, and solute concentration gradients): the effect of these parameters is however not fully understood, but it is well known that the susceptibility of these alloys to stress corrosion cracking decreases with ageing time $[5,6]$. 


\section{Materials and procedures}

A commercial 7075 alloy has been used in this work, having the following chemical composition (wt \%): $6.5 \mathrm{Zn}$; 2.7 Mg; 1.5 Cu; 0.21 Cr; 0.045 Mn; 0.14 Fe; 0.08 Si; 0.01 Ti.

The retrogression and re-ageing heat treating (RRA) was applied to the material in the T6 temper (aged for $24 \mathrm{~h}$ at $120^{\circ} \mathrm{C}$ ). The samples in the T6 temper were subjected to the retrogression at $160,180,200$ and $220^{\circ} \mathrm{C}$ for the time necessary for the minimum hardness to be obtained, which was 29, 9, 2 and $0.5 \mathrm{~min}$, respectively. The re-ageing treatments consisted of a stage at $120^{\circ} \mathrm{C}$ for $24 \mathrm{~h}$ for the retrogression at 200 and $220^{\circ} \mathrm{C}$ and $38 \mathrm{~h}$ for the retrogression at 160 and $180^{\circ} \mathrm{C}$. Mechanical and stress corrosion cracking strength obtained after the RRA were higher than those characteristic of the T6 temper [1,2]. The stress corrosion cracking strength of the RRA material, evaluated by the stress intensity factor at which the crack growth rate decreased to $10^{-10} \mathrm{~m} / \mathrm{s}$, rises with retrogression temperature, but remains inferior to that of the $\mathrm{T} 7$ temper value.

Bright and dark field transmission electron microscopy (TEM), selected area electron diffraction (SAED) and differential scanning calorimetry (DSC) were the tools used for microstructural characterization.

The literature identifies the precipitates found in the microstructure of this alloy as the following: the equilibrium precipitate $\mathrm{MgZn}_{2}, \eta$, with a hexagonal crystal structure and an incoherent interface with the matrix; the metastable precipitate, $\eta^{\prime}$, with a composition and crystal structure close to that of $\mathrm{MgZn}_{2}$, but with a semi-coherent interface with aluminium; and Guinier Preston Zones, GP zones, with a composition close to that of $\mathrm{MgZn}$, fully coherent with the matrix; the GP zones do not cause diffraction spots. The $\eta$ and $\eta^{\prime}$ precipitates were identified by SAED through their orientation relationship to the aluminium matrix and their lattice parameter; the data collected from the literature [7], being presented below:

1. the diffraction spots found in the present work were consistent with the lattice parameters: $a=5.21$ and $c=8.6 \AA$ for $\eta ; a=4.96$ and $c=14.03 \AA$ for $\eta^{\prime}$;

2 . the equilibrium precipitate may appear with eleven different orientation relationships to the matrix, although only the following three were observed: $\eta_{1}-\{00.1\} / /$ $\{110\}_{\mathrm{Al}}$ and $\{10.0\} / /\{001\}_{\mathrm{Al}} ; \eta_{2}-\{00.1\} / /\{111\}_{\mathrm{Al}}$ and $\{10.0\} / /\{011\}_{\mathrm{Al}} ; \eta_{4}-\{11.0\} / /\{111\}_{\mathrm{Al}}$ and $\{00.1\} / /$ $\{011\}_{\mathrm{Al}}$;

3. one single orientation relationship between the metastable $\eta^{\prime}$ precipitate and the matrix is reported and observed: $\eta^{\prime}-\{00.1\} / /\{111\}_{\mathrm{Al}}$ and $\{10.0\} / /\{011\}_{\mathrm{Al}}$.

Thin foils for TEM were prepared after heat treating. The samples were obtained by electrolytic polishing in a 'Tenupol' double jet electropolishing set. Electropolishing was performed at room temperature under $10 \mathrm{~V}$ and a 0.2 A current in a $25 \%$ (volume) solution of nitric acid in methanol. A HITACHI H90000-NA TEM with a high- resolution objective, operating under $360 \mathrm{kV}$, was used for the study.

A thermal analysis processing unit 'Mettler TC 11' equipped with a module for DSC 'Mettler DSC 27 HP' was used for the DSC experiments. The tests were run under a nitrogen atmosphere; a heating rate of $10^{\circ} \mathrm{C}$ per minute in the temperature range from 25 to $550^{\circ} \mathrm{C}$ being used. Discshape samples with $50 \mathrm{mg}$ mass were previously subjected to heat treating and then tested enclosed in aluminium capsules. A 7000 series Perkin Helmer DSC capable of starting the tests at $0^{\circ} \mathrm{C}$ was used for the samples in the $\mathrm{W}$ temper (solution treated) and after ageing at room temperature, since reactions at temperatures close to $20^{\circ} \mathrm{C}$ were expected in these cases.

\section{Results and discussion}

The DSC results are presented in Table 1, where the peak temperatures and enthalpy associated with each reaction are indicated; peak temperatures representing the maximum reaction rate temperature; enthalpy being measured by the area under the peak, proportional to the volume fraction of precipitate undergoing dissolution or formation.

\subsection{Solution treated}

The calorimetric curve after solution treatment is presented in Fig. 1, the curve showing four exothermic peaks, corresponding to several precipitation reactions, and a broad endothermic peak, at high temperature, corresponding to a dissolution reaction.

The precipitation from a saturated solid solution (sss) in the 7075 alloy occurs in the following sequence:

sss $\Rightarrow$ GP zones $\Rightarrow \eta^{\prime} \Rightarrow \eta$

The first peak observed must then correspond to GP zones formation; the second to $\eta^{\prime}$; and the third to $\eta$; whilst the

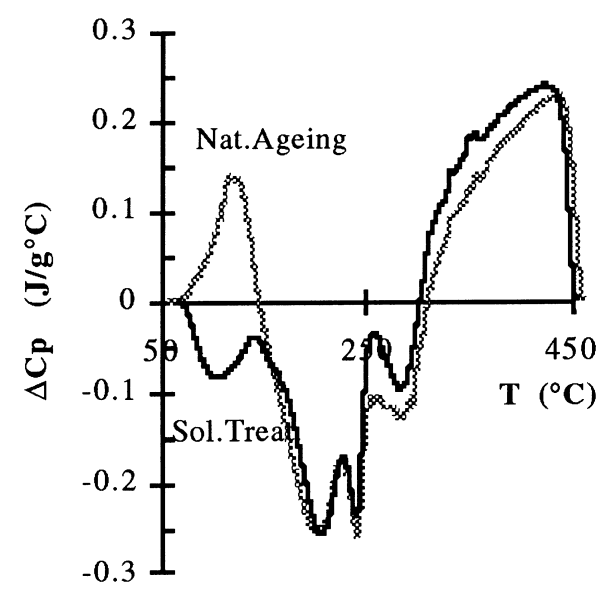

Fig. 1. Calorimetric curves of 7075 alloy after solution treatment and after natural ageing for ten days. 
Table 1

DSC results

\begin{tabular}{|c|c|c|}
\hline Treatment & Temperature $\left({ }^{\circ} \mathrm{C}\right)$ & $\Delta H(\mathrm{~J} / \mathrm{g})$ \\
\hline \multirow[t]{5}{*}{ Solution treated } & 103 & 5.25 \\
\hline & 206 & 13.15 \\
\hline & 238 & 4.21 \\
\hline & 281 & 2.48 \\
\hline & 416 & 27.19 \\
\hline \multirow[t]{5}{*}{ Natural ageing } & 117 & 4.87 \\
\hline & 213 & 14.62 \\
\hline & 240 & 6.24 \\
\hline & 284 & 5.43 \\
\hline & 433 & 20.32 \\
\hline \multirow[t]{4}{*}{ T6 } & 191 & 7.72 \\
\hline & 230 & 2.50 \\
\hline & 257 & 2.97 \\
\hline & 402 & 23.20 \\
\hline \multirow[t]{2}{*}{$\mathrm{T} 7$} & 216 & 7.12 \\
\hline & 396 & 26.37 \\
\hline \multirow[t]{4}{*}{ Retrogression $160^{\circ} \mathrm{C}$} & 195 & 5.67 \\
\hline & 228 & 2.51 \\
\hline & 263 & 3.19 \\
\hline & 401 & 23.17 \\
\hline \multirow[t]{4}{*}{ Retrogression $180^{\circ} \mathrm{C}$} & 199 & 4.16 \\
\hline & 230 & 1.93 \\
\hline & 263 & 2.98 \\
\hline & 415 & 23.95 \\
\hline \multirow[t]{5}{*}{ Retrogression $200^{\circ} \mathrm{C}$} & 168 & 0.89 \\
\hline & 205 & 2.10 \\
\hline & 231 & 1.29 \\
\hline & 256 & 3.28 \\
\hline & 406 & 22.10 \\
\hline \multirow[t]{5}{*}{ Retrogression $220^{\circ} \mathrm{C}$} & 160 & 0.99 \\
\hline & 199 & 2.16 \\
\hline & 230 & 2.26 \\
\hline & 253 & 2.90 \\
\hline & 403 & 24.16 \\
\hline \multirow[t]{4}{*}{ RRA $160^{\circ} \mathrm{C}$} & 194 & 7.99 \\
\hline & 230 & 1.96 \\
\hline & 263 & 2.61 \\
\hline & 400 & 22.90 \\
\hline \multirow[t]{4}{*}{ RRA $180^{\circ} \mathrm{C}$} & 194 & 7.69 \\
\hline & 230 & 1.82 \\
\hline & 264 & 3.39 \\
\hline & 399 & 20.60 \\
\hline \multirow[t]{4}{*}{ RRA $200^{\circ} \mathrm{C}$} & 198 & 7.78 \\
\hline & 230 & 0.82 \\
\hline & 263 & 2.71 \\
\hline & 402 & 21.14 \\
\hline \multirow[t]{4}{*}{$\mathrm{RRA} 220^{\circ} \mathrm{C}$} & 198 & 7.40 \\
\hline & 228 & 1.26 \\
\hline & 263 & 3.64 \\
\hline & 409 & 22.21 \\
\hline
\end{tabular}

fourth exothermic peak, according to DeIasi and Adler [8], being a consequence of the $\eta$ growth by Ostwald ripening; and the final peak is the result of $\eta$ dissolution.

\subsection{Natural ageing}

After natural ageing for 10 days, the calorimetric curve, also presented in Fig. 1, is quite similar to that of the solution treated sample, except for the existence of a low

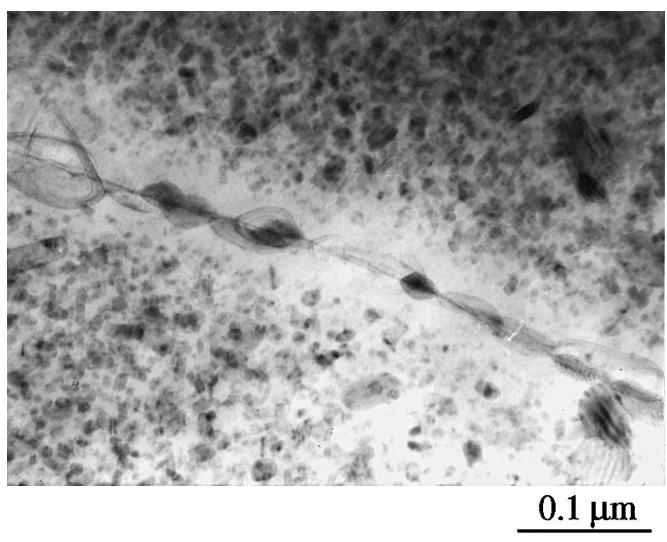

Fig. 2. TEM microstructure of overaged T7 temper.

temperature endothermic peak instead of that resulting from the GP zones formation. The GP zones formed during natural ageing are undergoing a dissolution process that overlaps their formation peak.

\section{3. $T 7$ temper}

The microstructure observed in TEM for the overaged T7 temper shows a rather coarse and uniformly distributed precipitation inside the grains, as shown in Fig. 2; the grain boundary precipitates being coarser and more spaced.

The SAED patterns from the T7 temper reveal several spots from the equilibrium precipitate $\eta$ and less from $\eta^{\prime}$; the precipitates are essentially $\eta$; with $\eta^{\prime}$ precipitates being present in a smaller extent.

The calorimetric curves of the $\mathrm{T} 7$ temper, presented in Fig. 3, show two endothermic reactions; the low temperature peak resulting from the $\eta^{\prime}$ dissolution process and the high temperature peak from the $\eta$ dissolution reaction. These results are in agreement with the TEM microstructural characterization.

\subsection{T6 temper}

In the T6 temper the TEM micrographs reveal a very fine precipitation distributed homogeneously inside the grains

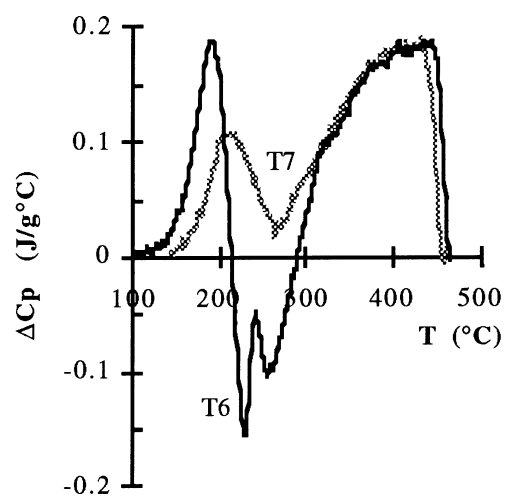

Fig. 3. Calorimetric curves of the $\mathrm{T} 7$ and $\mathrm{T} 6$ temper. 


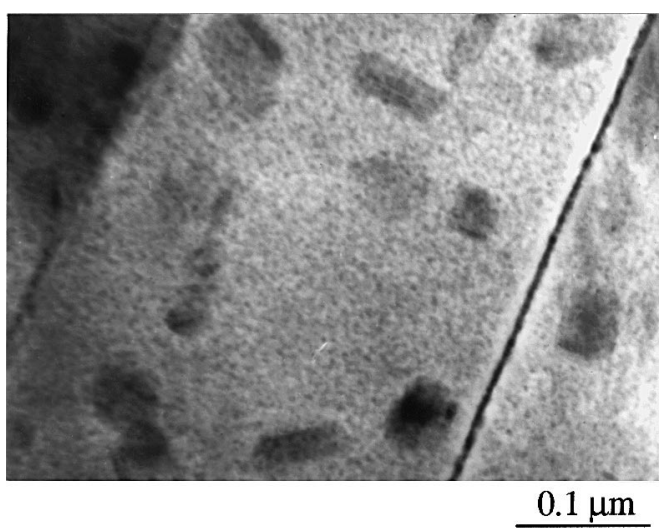

Fig. 4. TEM microstructure of the T6 temper.

with coarser and less spaced grain boundary precipitates, as can be seen in Fig. 4.

The spots in the SAED pattern of the T6 temper, an example of which is presented in Fig. 5, are mainly from $\eta^{\prime}$ : this reveals a high volume fraction of this precipitate.

Dark fields from the $\eta$ and $\eta^{\prime}$ spots showed a precipitation density similar to that observed in bright field micrographs taken from the same sample region; these observations together with the analysis of the SAED patterns enable the presumption that $\eta^{\prime}$ is responsible for the majority of the precipitation: $\eta$ and GP zones should be present in smaller amounts.

$\mathrm{Al}-\mathrm{Zn}-\mathrm{Mg}$ alloys have been mostly used for the study of the precipitation of aluminium precipitation hardenable alloys using SAED and X-ray diffraction; $1.5 \mathrm{wt} \%$ copper has been added in same cases to these alloys, the chemical composition of which then becomes similar to the 7075 alloy studied in this work. It is reported that copper addition accelerates the precipitation process as well as the high temperature limit stability of $\eta$ and $\eta^{\prime}[9,10]$; the equilibrium precipitate forms at temperatures in the 200 to $300^{\circ} \mathrm{C}$ range and dissolves at temperatures higher than $300^{\circ} \mathrm{C}$. Since the T6 temper is attained by ageing for $24 \mathrm{~h}$ at $120^{\circ} \mathrm{C}$, it is reasonable to accept that the majority of the precipitates are $\eta^{\prime}$, as determined in the present work.

The calorimetric results of the T6 temper in this work are in close agreement with those in the literature $[8,11,12]$ in respect of the peak temperatures and the enthalpy involved in the different reactions. The curves show an endothermic peak at $191^{\circ} \mathrm{C}$, followed by an exothermic region with two partial overlapped peaks at 230 and $257^{\circ} \mathrm{C}$ and finally a large broad peak at high temperature, as presented in Fig. 3. Based on the work of DeIasi and Adler [8], the literature explains the first peak as GP zones dissolution, partially overlapped with the precipitation of $\eta^{\prime}$; the exothermic peak at $230^{\circ} \mathrm{C}$ as the precipitation of $\eta^{\prime}$ and $\eta$; the exothermic peak at $257^{\circ} \mathrm{C}$ as the coarsening of $\eta$ by an Ostwald ripening process overlapped with the dissolution of $\eta^{\prime}$; and finally the high temperature endothermic peak as the $\eta$ dissolution.

This interpretation results from studies of the microstructural evolution for a T6 temper during a heating cycle in a hot stage TEM similar to a DSC run; it should be noted that these authors based their conclusions on morphological aspects of the microstructures and not on diffraction results. They conclude that $95 \%$ of the precipitates are GP zones and $5 \%$ are $\eta^{\prime}$. According to the present results, the greater part of the precipitates in the T6 temper are $\eta^{\prime}$ : GP zones and $\eta$ should be present in smaller amounts. In view of the present results the DSC curves can be interpreted as follows: the first endothermic reaction is a result of dissolution of $\eta^{\prime}$ and GP zones: as the temperature is raised the dissolution of the coarser, and so more stable $\eta^{\prime}$, overlaps the $\eta$ precipitation occurring during the low temperature exothermic peak; whilst the $257^{\circ} \mathrm{C}$ exothermic peak is the result of the $\eta$ Ostwald ripening process. Finally, $\eta$ dissolution is revealed by the high temperature endothermic peak.

\subsection{Retrogression}

The microstructures after retrogression are very similar for the four temperatures tested. The precipitation inside the grains is similar to that of the T6 temper, whilst the grain
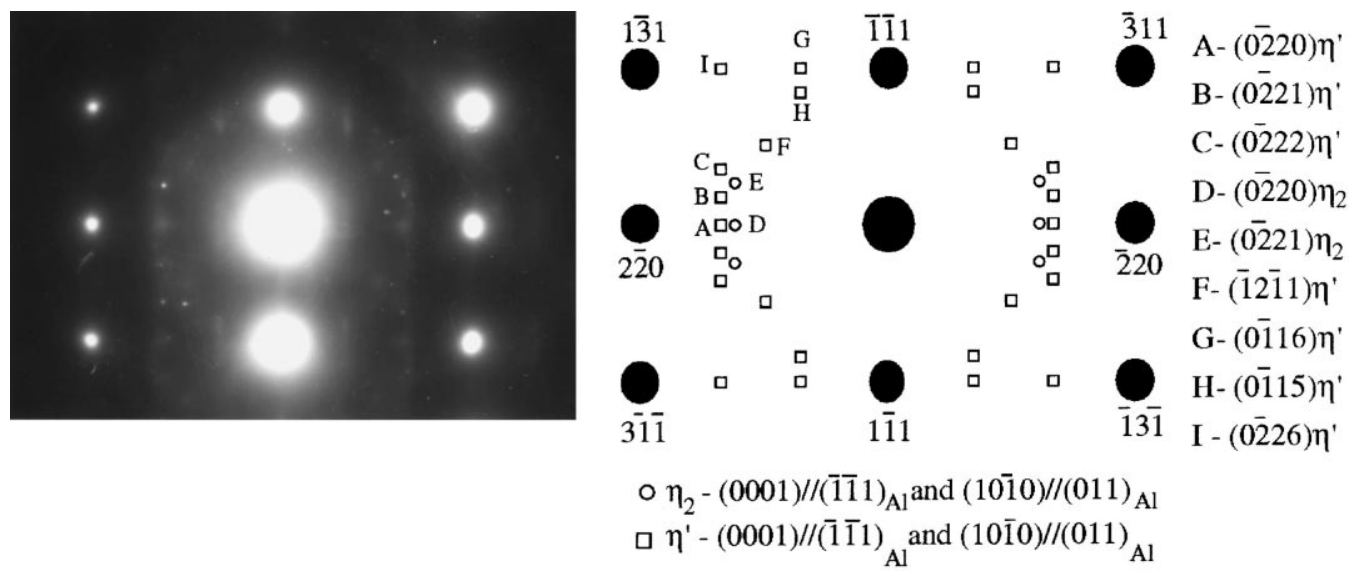

Fig. 5. SAED pattern of the T6 temper taken from the $\langle 112\rangle$ direction. 


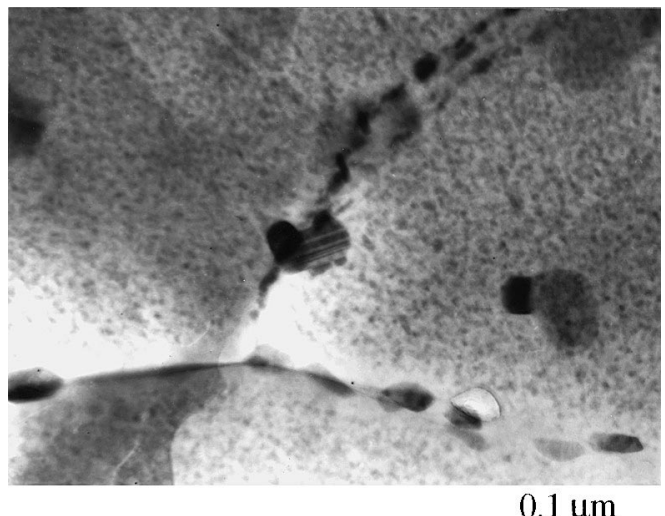

$0.1 \mu \mathrm{m}$

Fig. 6. TEM microstructure after retrogression at $200^{\circ} \mathrm{C}$.

boundaries show very coarse precipitates well apart, very similar to the $\mathrm{T} 7$ temper grain boundary precipitation, as presented in Fig. 6; these observations leading to the conclusion that the grain boundary precipitates have followed a coarsening process.

After retrogression the SAED pattern showed a lower number of $\eta^{\prime}$ diffraction spots relatively to those in the T6 temper: the softening occurring during retrogression may then be explained by $\eta^{\prime}$ dissolution.

After retrogression the samples presented a behaviour in the DSC runs that depended on the retrogression temperature, as can be seen in Fig. 7. For retrogression temperatures greater than $180^{\circ} \mathrm{C}$ the curves showed a first small exothermic peak followed by the same peaks as for the T6 temper: the first endothermic peak occurs at a temperature $10^{\circ} \mathrm{C}$ higher and is smaller than that of the T6 temper, as can be seen in Table 1. These two aspects of the calorimetric curves are a result of the dissolution process, during retrogression, of the less stable precipitates (GP zones and the smaller $\eta^{\prime}$ particles). The excess solute in the solid solution is responsible for the re-precipitation that occurs in the DSC run, from which the small exothermic peak results: since the $\eta^{\prime}$ remaining in the microstructure after retrogression has a smaller volume fraction and is more stable, the dissolution peak is displaced to higher temperatures and is associated

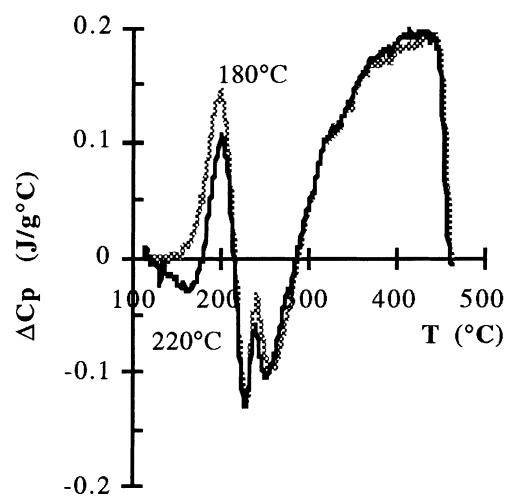

Fig. 7. Calorimetric curves after retrogression at 180 and $220^{\circ} \mathrm{C}$. with a smaller enthalpy value than that presented by the T6 temper.

For retrogression temperatures lower or equal to $180^{\circ} \mathrm{C}$, the calorimetric curves have the same peaks of the T6 temper, but do not show the first small exothermic peak that appears after retrogression at higher temperatures. Even if the dissolution during the retrogression treatment is insufficient for the precipitation process to occur in the DSC run, it is clear that the dissolution occurred because the $\eta^{\prime}$ dissolution peak is displaced to higher temperatures and is associated with a smaller enthalpy value than that of the T6 temper.

It becomes clear that dissolution of the less stable precipitates, GP zones and the smaller $\eta^{\prime}$ particles, occurred at all retrogression temperatures, the extent of this dissolution being controlled by the retrogression temperature.

Similar results were obtained by other authors during retrogression at higher temperatures. Habiby et al. [13] did not find any microstructural changes after retrogression for $1 \mathrm{~min}$ at $230^{\circ} \mathrm{C}$; whilst Park and Ardell [4] detected dissolution of $1 / 3$ of the smaller precipitates and growth of the coarser precipitates during retrogression at $240^{\circ} \mathrm{C}$; the final microstructure having a lower density of more stable precipitates, less $\eta^{\prime}$ and more $\eta$.

\subsection{Retrogression and re-ageing}

Re-ageing promotes a very dense precipitation inside the grains whilst the grain boundary precipitates continue the growth process initiated during retrogression (see Fig. 8): no effect of retrogression temperature was detected. The RRA microstructure is similar to that for the T6 temper, but is a little coarser and denser inside the grains: contrarily, the grain boundary precipitation is quite different, and very similar to that of the overaged $\mathrm{T} 7$ temper.

From the SAED pattern analysis it became clear that $\eta^{\prime}$ reprecipitation occurred during re-ageing, since the diffraction spots due to this precipitate increased.

Accordingly to Park and Ardell [4] during re-ageing a precipitation of $\eta^{\prime}$ occurs, whilst its coarser particles trans-

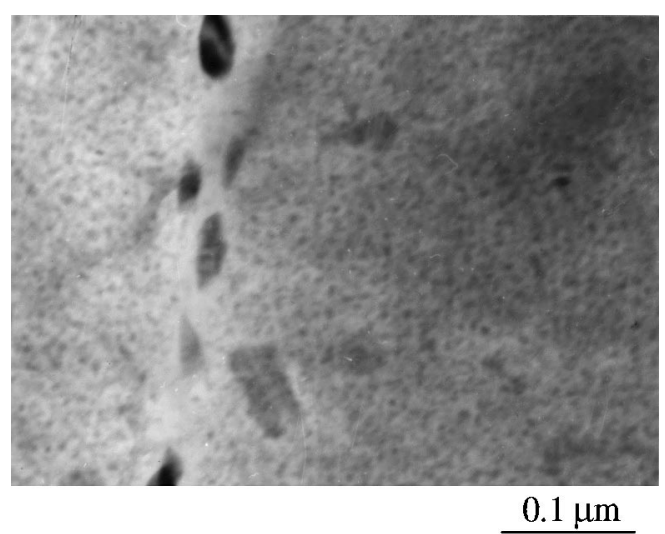

Fig. 8. TEM microstructure after RRA (retrogression at $180^{\circ} \mathrm{C}$ ). 


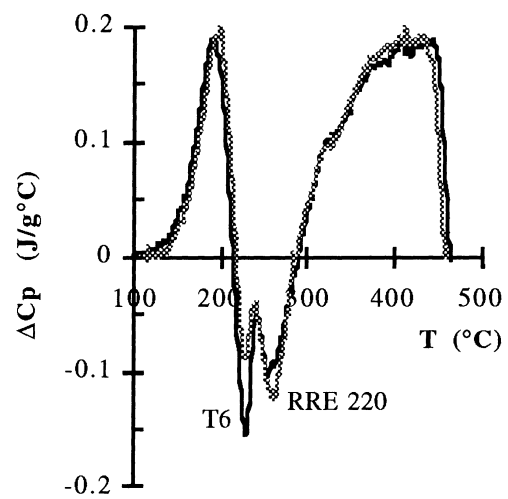

Fig. 9. Calorimetric curves of the T6 temper and RRA (retrogression at $\left.220^{\circ} \mathrm{C}\right)$.

form to $\eta$. Rajan et al. [3] made microstructural observations that are similar to those in this work: the RRA microstructures are similar to those for the T6 temper inside the grains and are similar to those for the $\mathrm{T} 7$ temper in the grain boundaries.

The calorimetric curves after RRA present the same peaks of the T6 temper, as can be seen in Fig. 9. Differences of the curves after retrogression can be found with the help of the data from Table 1. The enthalpy associated with the first endothermic peak is higher and similar to that presented by the T6 temper; the increase of the enthalpy values during reageing being the direct result of the precipitation process already detected by electron diffraction. Differences relatively to the T6 temper are found in the exothermic region of the curves: the enthalpy associated to $\eta$ formation peak (the first exothermic one) being lower, indicating a higher volume fraction of this precipitate. As the retrogression temperature rises, the enthalpy value becomes lower, indicating a higher volume fraction of $\eta$, and so a more stable microstructure develops at higher retrogression temperatures after re-ageing.

Calorimetric results from other authors $[12,14]$, are similar to those presented here; retrogression and re-ageing treatments promote similar microstructures to the T6 temper but they are more stable.

\section{Conclusions}

The microstructural characterization of 7075 alloy in the RRA temper responsible for the high mechanical strength and the improved stress corrosion cracking resistance was the main objective of this work. The results attained allow the following to be concluded.

1. The T6 temper microstructure is characterized by a high density of fine precipitates distributed homogeneously in the aluminium matrix; the precipitates essentially being $\eta^{\prime}$; with small amounts of GP zones and $\eta$ being present.

2. Retrogression is responsible for the dissolution of the less stable precipitates (GP zones and the finer particles of $\eta^{\prime}$ ) inside the grains; the extent of the dissolution process being controlled by the retrogression temperature. (temperatures higher than $180^{\circ} \mathrm{C}$ are more efficient in dissolving the precipitates); the grain boundary precipitates growing and becoming more spaced.

3. Re-ageing promotes the re-precipitation of $\eta^{\prime}$ whilst its pre-existent particles grow and transform to $\eta$. Inside the grains the microstructure is similar to that of the T6 temper, but is slightly denser and coarser and more stable in nature. The $\eta$ volume fraction rises during RRA; the grain boundary precipitates growth continues and the final grain boundary microstructure is similar to that of the overaged $\mathrm{T} 7$ temper.

4. The retrogression temperature influences the microstructural stability after re-ageing: the greater the retrogression temperature, the more stable is the microstructures obtained after re-ageing.

\section{Acknowledgements}

The authors are grateful to Professor Paiva Martins from FEUP and Professor Cruz Pinto from U. Minho, for authorizing the use of DSC equipment. This work had financial support from JNICT (PBIC/T/C/CTM/1424/92).

\section{References}

[1] F. Viana, A.M.P. Pinto, H.M.C. Santos, Proc. 7th Nat. Meet. of the Portuguese Mats. Soc. 1 (1995) 42.

[2] F. Viana, A.M.P. Pinto, to be published in the Proc. 8th National Meeting of the Portuguese Mats. Soc., 1997.

[3] J.K. Rajan, W. Wallace, J.C. Beddoes, J. Mater. Sci. 17 (1982) 2817.

[4] J.K. Park, A.J. Ardell, Metall. Trans. 15A (1984) 1531.

[5] W. Hepples, M.R. Jarret, J.S. Crompton, N.J.H. Holroyd, In: Proc. Environment-Induced Cracking of Mets., 1989, 383 p.

[6] N.J.H. Holroyd, In: Proc. Environment-Induced Cracking of Mets., 1989, $311 \mathrm{p}$.

[7] D.W. Edington, Typical Electron Microscope Investigations, Philips Technical Library, 1976.

[8] R. Deiasi, P.N. Adler, Metall. Trans. 8A (1977) 1177.

[9] Á. Cziráki, B. Fogarassy, I. Geröcs, Light Materials for Transportation Systems, N.J. Kim (Ed.), Center for Advanced Aerospace Materials, 1993, p. 391.

[10] P. Auger, J.M. Raynal, M. Bernole, R. Graf, Mem. Sci. Rev. Met. 71 (1974) 557.

[11] J.M. Papazian, Metall. Trans. 13A (1982) 761.

[12] U. Batra, S.R. Prabhakar, Trans. Indian Inst. Met. 48 (1995) 55.

[13] F. Habiby, A. Ul Haq, F.H. Hashmi, A.Q. Khan, Metall. Trans. 18A (1987) 350.

[14] A. Baldantoni, Mater. Sci. Eng. L5 (1985) 72. 